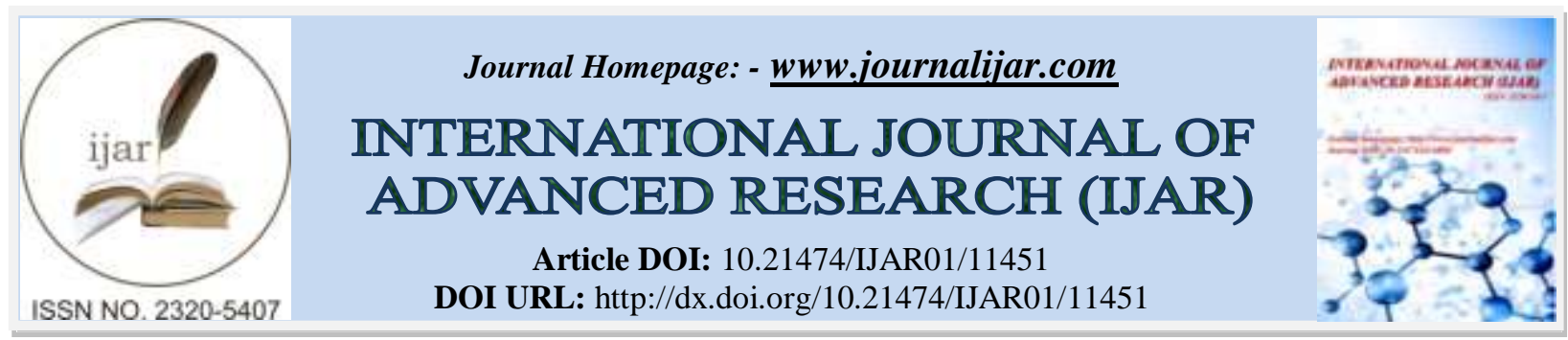

RESEARCH ARTICLE

\title{
CUSTOMER OPINION ASSESSMENT USING ARTIFICIAL NEURAL NETWORKS AND MACHINE LEARNING
}

\author{
Amit Ganesh Upadhye ${ }^{1}$ and A.C Lomte ${ }^{2}$ \\ 1. Student, Computer Engineering, JSPM's BSIOTR, Pune, India. \\ 2. Professor, Computer Engineering, JSPM's BSIOTR, Pune, India.
}

\section{Manuscript Info}

.........................

Manuscript History

Received: 31 May 2020

Final Accepted: 30 June 2020

Published: July 2020

Key words:-

Customer Feedbacks, Artificial Neural Networks

\section{Abstract}

The consumer service has to be provided for every kind of product and organization. Be it day to day basic smartphone or high end car, its always backed up by the customer support team who is with consumer from the day one of the purchase. The support team takes care of introducing buyer to the new product, providing necessary details about functionality and features. As the product gets older, it requires maintenance and then service centers, customer support team pitches again. Most of the time customer at least visits authorized service centers until product is in warranty before seeking help from someone novice. In this complete lifecycle of product apart from product itself consumer does have fair number of interactions with support team, and this support team is always considered as single point of contact and owner for anything that goes wrong with product. Considering this huge part of customer support to make remarkable impact on how that product is going to perform in future is important factor. With the help of artificial neural network its possible to understand what went fantastic or awful when dealing with customers in past, this historic data can be used to train neural networks to avoid such mistakes to thrive on consumer service satisfaction.

Copy Right, IJAR, 2020,. All rights reserved.

\section{Introduction:-}

Nowdays most of the organizations have a way for customer to provide feedback. Those could be in form of the phone calls or emails, even transport network like Uber, Ola also depends on consumer feedback and likewise driver is preferred for the subsequent rides. The satisfaction is difference between what is provided as service/product versus what is expected, the difference can be positive or negative for any individual. One can even call it as expectations, and these exceptions are constantly changing and never satisfied. The customer service satisfaction is important for business success and the positive customer satisfaction has impressive effects on profitability of every business [1]. Many times dissatisfaction of one specific feature or service causes overall dissatisfaction product or service, as example a smartphone is overall good but camera does not work properly at night. Even though camera gives perfect pictures in daylight there is possibility that user is not well satisfied because of this behavior.

The aim is to process consumer feedback, opinions provided on the support cases to learn about different attributes that contributed to positive or poor customer experience. Later on when customers will contact the support department, these historic factors can be used to improvise interaction between customer and the support 
representative. The incident raised by customer has multiple important attributes, i.e. private comments, Service Level Agreement, number of public comments, number of times support department did not met the SLA, escalation type and number of escalations, recent customer feedback and rating. The artificial neural networks are used to train on historic data available of customers and then provide classification, guidelines on the current ongoing case comparing to that. There are already tools like TextBlob and Naive Bayes which has been tried to achieve similar goals. The artificial neural networks and Naive Bayes have different ways to treat and process data, we compare both of them with finite results and calculations.

\section{Literature Review:-}

Consumer happiness is important factor in the marketing department. The another interesting factor to consider is behavior of customer as per the experience and exceptions of products or services. Its the habit of customer to spread a word about excellent services [2]. Text mining or data processing from collection of structured text(also called as opinions) has been tried and applied on twitter accounts [3]. Machine learning techniques has been applied on views of two political parties to collect neutral, positive and negative views. This type of machine learning structure can help to alternate political strategies [3] . The Naive Bayes, support vector machines and random forest has used on unique data to prove the algorithmic process[3].

Text mining or retrieval of data from a collection of documents stores frequently with the help of analysis tools or manuals [13] . Through the analysis process of several text mining perspectives, information can be produced that can be used to increase profits and services.

Typically user checks for reviews and feedback about the products online before making decision to purchase it. This type of analysis is focused research area in data mining and machine learning. There is huge surge of opinions which includes exact facts and views about specific product or service[4]

Most of the service industries focus on providing best service or products concentrates on having static guidelines when it comes to consumer support and answering queries. The customer support department depends heavily in static guidelines [5]. In any customer service organization time to close, average escalations from customers affect the overall quality of service [5]. A. Consumer satisfaction information:

The American Express Global Customer service Barometer is reputed survey conducted from nine countries. This captures experiences with consumer service. Survey is conducted from sample of thousand customers who are eighteen plus in age from different countries. The surveys are calculated with three years cadence cycle, below are the important facts to consider from 2014 survey[6],

1. Fig 1. shows only six customers out of ten believe that organizations meet satisfaction exceptions. Surprisingly only five percent of users said that companies go beyond the satisfaction exceptions.

2. Fig 2. displays two of five users feel companies dont pay attention providing better service. Lowered from seven percent in 2012 and six percent in 2011, five percentage of customer mentions that the customer service experiences they have with companies normally 'exceed their expectations'. 


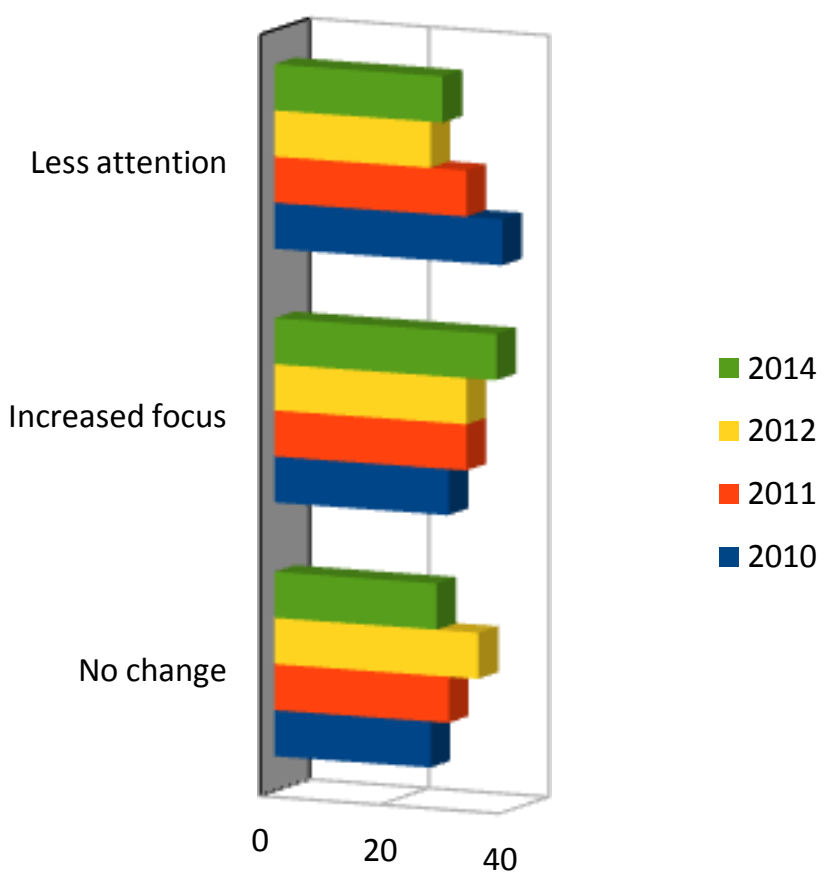

Fig 1:- Graph to display ratio of meeting satisfaction.

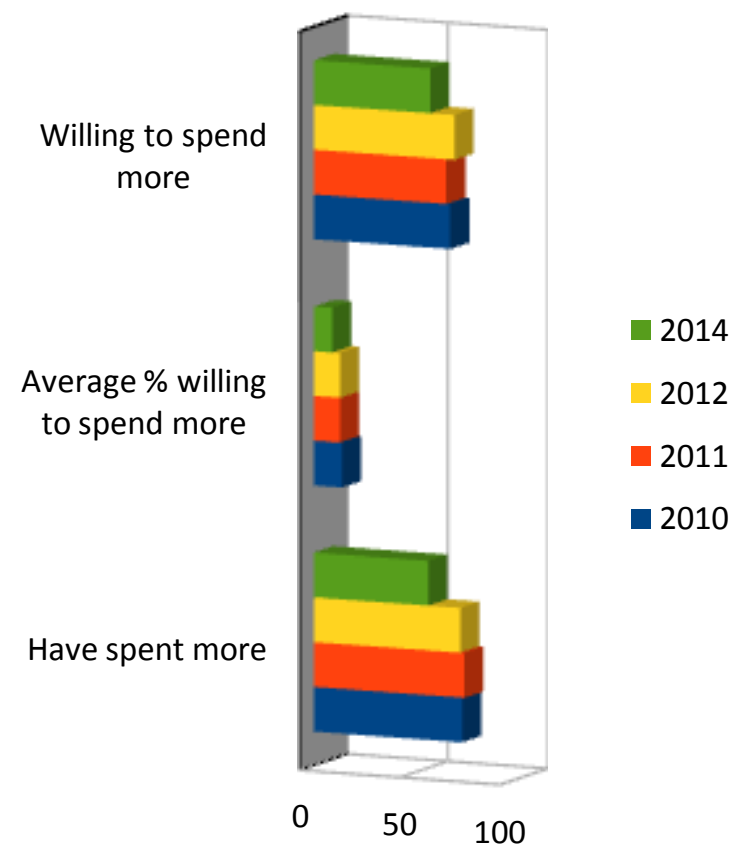

Fig 2:- The change of customer satisfaction focus.

Below are the details about 2017 customer support barometer by 'American Express' [7],

1. Two in three or sixty six percentage of Singaporeans users did not proceed to buy product because of awful customer services. Considering this over sixty seven percentage of customers are fine to deal with two or more poor experiences to before changing the product or service. 
2. Over $72 \%$ consumers willing to pay $16 \%$ more because of excellent service and $65 \%$ have already paid more because of same.

3. Consumers tells 24 people about worst customer service experience and exactly opposite to this they share good experiences with only 12 persons.

4. Customers appreciate speed of service, personalization and getting aware about products or services they use.

Approaches used for customer satisfaction analysis:

[8] This paper introduces Naive Bayes as probabilistic calculation method. This method has been applied on the TripAdviser website data. The TripAdviser is old portal for hotel bookings and has listing of more than 200 hotels and around 30 destinations. It also provides bookings for more thank 74 thousand attractions. The TripAdviser reviews are considered to be processed in model where those are downloaded with the help of crawling from website, and then data is reviewed. Below is stated mathematical model of Naive Bayes,

$$
\begin{aligned}
& \text { Pricision }=\frac{\mathrm{TP}}{(\mathrm{TP}+\mathrm{FP})} \\
& \text { Recall }=\frac{\mathrm{TP}}{(\mathrm{TP}+\mathrm{FN})} \\
& \text { Accuracy }=\frac{(\mathrm{TP}+\mathrm{TN})}{(\mathrm{TP}+\mathrm{TN}+\mathrm{FP}+\mathrm{FN})}
\end{aligned}
$$

Where,

$$
\begin{aligned}
& \text { TP = positive feedback classified as positive by method } \\
& \text { TN= negative feedback classified as negative by method } \\
& \text { FP= negative feedback classified as the positive(false positive) } \\
& \text { FN = positive feedback classified as negative(false negative) }
\end{aligned}
$$

[8] This paper has taken data of size 337, which means around 337 reviews were collected. Out of 337, 269 were used for the training data and 68 for testing data. The WEKA 3.8.2 version was used with Naive Bayes classifiers and compared with the Textblob tool which does sentiment analysis. The accuracy of Naive Bayes for these samples shows the accuracy of 72 percentage as compared to accuracy 69 percentage of Texblob. Considering this its concluded that Naive Bayes shows better results which are about 2.94 percent higher when dealing with sentiment analysis from the TripAdvisor comments.

\section{Research Method:-}

This paper takes data of customer support satisfaction which includes primary score of satisfaction, comment of the consumer, average escalations on case, average breaches of support level agreement, average number of comments on case and average days to close the case. The data is processed and analyzed using keras artificial neural network machine learning libraries.

A. Data processing and analysis,

Fig 3 shows the data processing using keras machine learning. 


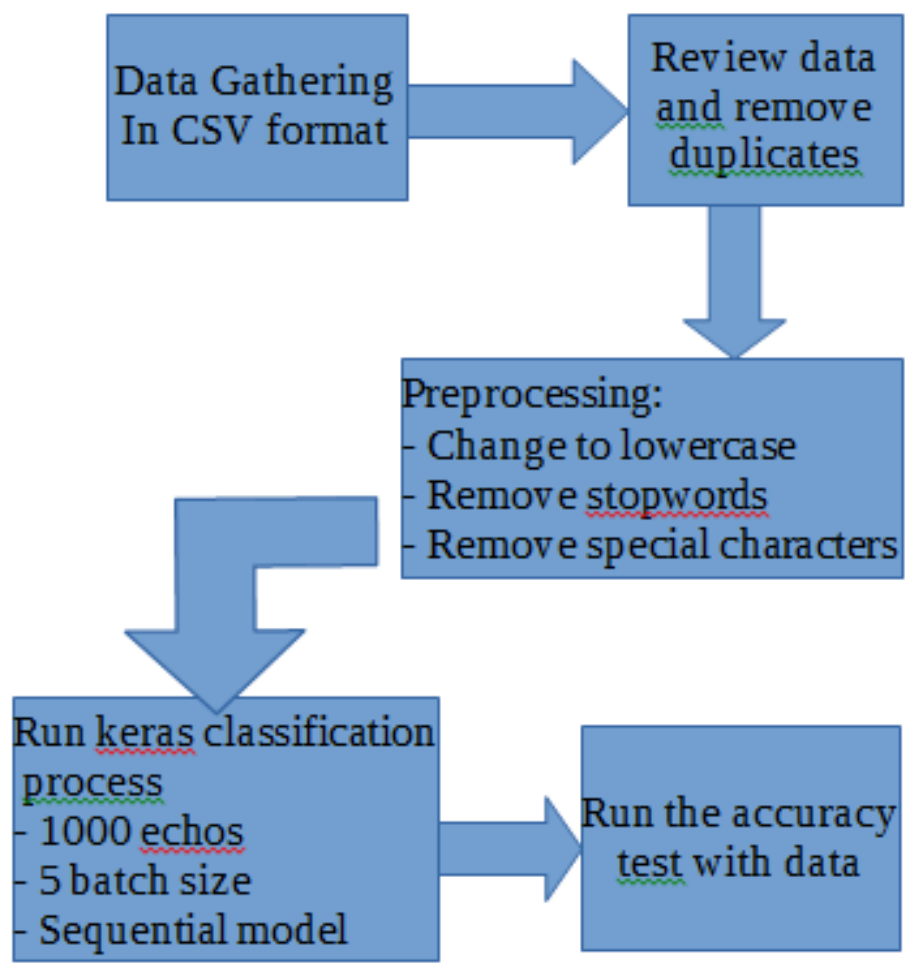

Fig 3:- Processing data with keras.

About 1500 samples of customer surveys are collected which has all the attributes available for data processing and analysis. The samples which are missing the attributes are neglected to get results which are on balanced data instead of filling the missing data with dummy attributes. These customer surveys are then mapped as per 'Good' word adjective ladder so its possible to have mapping between number and words. The ' 10 ' customer satisfaction survey is transformed to 'Superior' and ' 1 ' is transformed to 'Poor'. Fig 4. shows the mapping matrix between numerical and adjective,

\begin{tabular}{|l|l|}
\hline Numeric feedback & Feedback in word \\
\hline 10 & Superior \\
\hline 9 & Great \\
\hline 8 & Good \\
\hline 7 & Fine \\
\hline 6 & Decent \\
\hline 5 & Fair \\
\hline 4 & Average \\
\hline 3 & Mediocre \\
\hline 2 & Inferior \\
\hline 1 & Poor \\
\hline
\end{tabular}

Fig 4:- Shows the mapping of numerical feedback with adjective.

The Fig 5. shows the example of mappings of customer support reviews. Likewise data of more than 1500 instances are collected to feed keras machine learning,

\begin{tabular}{|l|l|}
\hline Comment & Score \\
\hline $\begin{array}{l}\text { Even though I was requesting help with a non-supported approach to the problem, the } \\
\text { analysts assisted me in a positive and constructive manner. }\end{array}$ & Superior \\
\hline $\begin{array}{l}\text { We found the issue as soon as we spent some time reading all the material for the } \\
\text { vulnerability. We had technically opened a security vulnerability by using an MFA } \\
\text { configuration. }\end{array}$ & \\
\hline Fast and clear & Superior \\
\hline
\end{tabular}




\begin{tabular}{|l|l|}
\hline Very easy, quick and thorough. & Superior \\
\hline Stable OS and good support. & Great \\
\hline Great support & Superior \\
\hline Support goal was to close ticket asap, not to fully understand what is the case. & Mediocre \\
\hline Ease of opening ticket and courteous support. & Great \\
\hline A bit to slow responses. Perhaps an issue with what I was expecting for a level 3 case. & Mediocre \\
\hline SLA not met for initial response (took more than 4 hours). & Good \\
\hline $\begin{array}{l}\text { John understood the problem I was having and he pointed me to exactly what I needed. } \\
\text { That was not the case with the 2 previous support engineers I dealt with. }\end{array}$ & Superior \\
\hline $\begin{array}{l}\text { This case experience is worst than bad. The Engineer was not more knowledgeable about } \\
\text { this product then myself. He ignored some of my question and recommendation. For } \\
\text { other question, he gave me answer like a second grader teacher give to his students. I } \\
\text { found the issue, fixed it. }\end{array}$ & Poor \\
\hline Friendly staff that are extremely knowledgeable & Superior \\
\hline $\begin{array}{l}\text { I was very pleased with the support I received. I was less than pleased with the amount of } \\
\text { time it took my ticket to be answered initially. }\end{array}$ & Great \\
\hline
\end{tabular}

Fig 5:- Sample of surveys and feedback mapping.

The Fig 6 shows architecture of neural network. With respect to this diagram input here is comment of the feedback provided by customer and output is how well that classify to adjective ladder of the satisfaction.

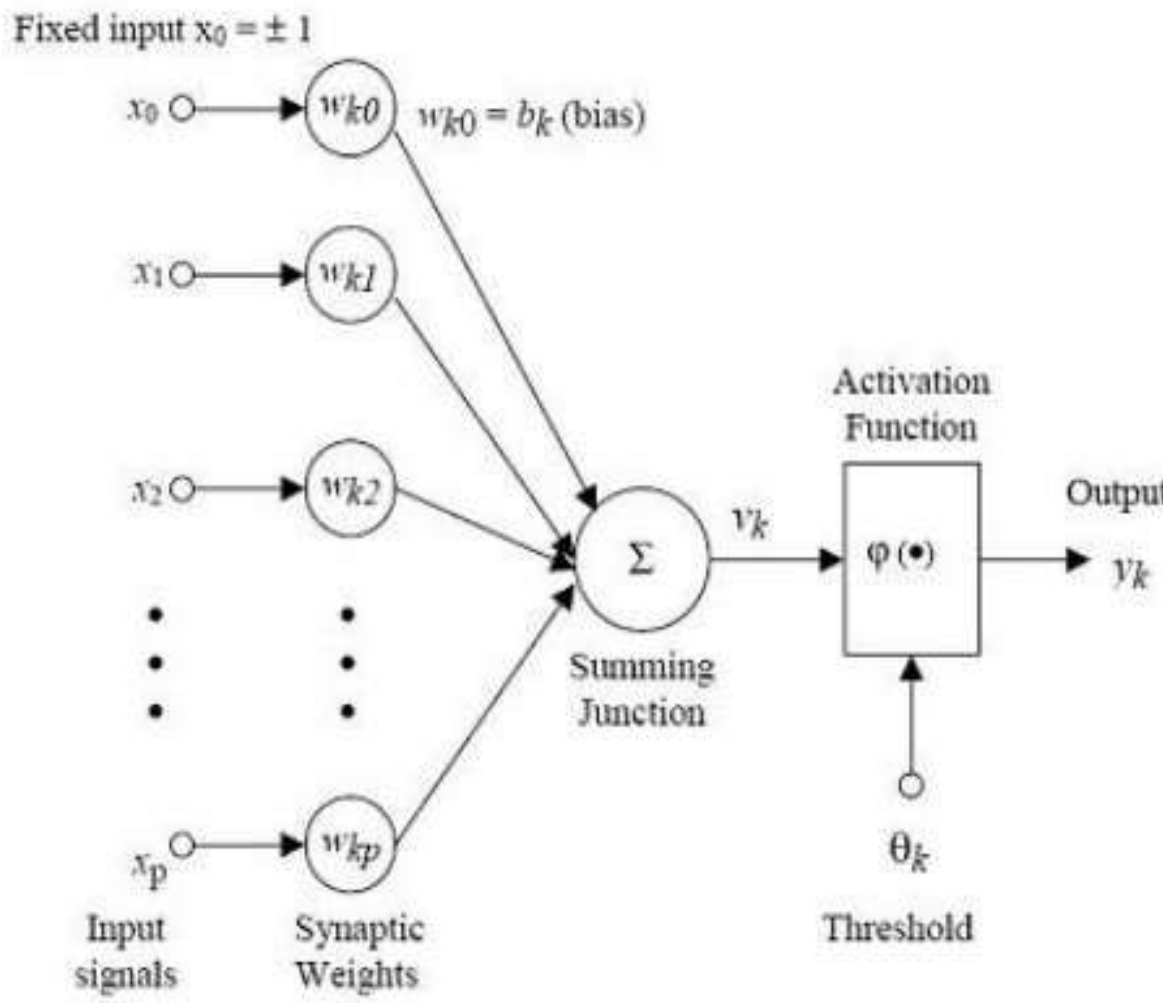

Fig 6:- architecture of the neural networks.

The neural network can be defined as mathematical model. The output of the neuron yk would be the outcome of some activation function of value vk.

$\mathrm{v}_{\mathrm{k}}=\sum_{\mathrm{j}=1}^{\mathrm{p}} \mathrm{W}_{\mathrm{kj}} \mathrm{X}_{\mathrm{j}}$ 
Here,

$$
\begin{aligned}
& \text { X - some input which can differ model to model } \\
& \text { W - weights given to neurons activation } \\
& \text { V - output after activation }
\end{aligned}
$$

The keras provide multiple options with respect to machine learning. In this process sequential model is selected which gives better results with text processing. After trying few combinations it shows that 100 epochs and 2 batch size works great with the data size of this. Out of 1500 set of surveys 80 percent which is 1200 is used for training the network, and 20 percentage which is 300 is used as test sample. Fig 7. shows the run and accuracy of the model, Fig. 7 keras output with training and test output

\section{Conclusion:-}

When two methods which are Naive Bayes and Artificial Neural Networks are compared to process the sentiments of customers, neural networks shows better results. The sentiment analysis done in [1] show the accuracy of Naive Bayes is $72.06 \%$ and Neural Network shows the accuracy as $80 \%$ which is more than $7 \%$ progress over formal proposed model in [1]. Furthermore research can be done to apply another data mining processes on this kind of data which may or may not provide better results.

\section{Acknowledgments:-}

I wish to thank my Project Guide, Prof. A. C. Lomte for her overwhelming encouragement and helpful feedback. Also, I would like to thank Head Of Department of Computer Engineering Prof. G. M. Bhandari who gave me opportunity to do this research project. Lastly, I would like to thank authors of various reference materials mentioned in the references for their commendable research.

\section{References:-}

1. K Ilieska, "Customer satisfaction index--as a base for strategic marketing management," TEM Journal, vol. 2, no . 4, p. 327, 2013 .

2. A. Hasan, S. Moin, A. Karim, and S. Shamshirband, "Machine learning-based sentiment analysis for twitter accounts," Mathematical and Computational Applications, vol. 23, no . I, p. 11,2018.

3. A. Hasan, S. Moin , A. Karim, and S. Shamshirband, "Machine learning-based sentiment analysis for twitter accounts," Mathematical and Computational Applications, vol. 23, no . I, p. 11,2018.

4. R. Feldman, "Techniques and applications for sentiment analysis ," Communications ofthe ACM, vol. 56, no. 4, pp . 82-89,2013.

5. Customer Zodiac - A Way to Understand Customer Pain Points to Improve Customer Service Satisfaction. International Journal of Advanced Research in Computer and Communication EngineeringVol. 4, Issue 12, December 2015

6. "GLOBAL CUSTOMER SERVICE BAROMETER - 2014". Online Available at http://about.americanexpress.com/news/docs/2014x/2014-Global-Customer-Service-Barometer-US.pdf

7. "American Express Global Customer Barometer 2017" Online Available at https://business.americanexpress.com/sg/ /media/Files/GCP/sg2/business-trendsinsights/Amex_GCSB_Infographics.pdf

8. Sentiment Analysis of Restaurant Customer Reviews on TripAdvisor using Naive Bayes 12th International Conference on Information \& Communication Technology and System (ICTS) 2019. 